\title{
Adolescents' Value of Children and Their Intentions to Have Children: A Cross-Cultural and Multilevel Analysis
}

\author{
Boris Mayer' and Gisela Trommsdorff'
}

\begin{abstract}
This study contributes to research regarding the value of children (VOC) by comparing adolescents' $\mathrm{VOC}$ and their intentions to have children across 12 cultures and by exploring the relations between these constructs at the individual and cultural levels using multilevel modeling. A total of 3,348 adolescents from 12 cultures participated in this study. On average, adolescents reported that they intended to have about two children and also reported emotional VOC as being highly important. Adolescents from cultures with a low as compared to a high level of economic development reported a higher importance of the utilitarian-normative VOC. Results of the multilevel analyses showed that the reported emotionalVOC was positively related to the number of children adolescents intended to have at the individual level, whereas the utilitariannormative VOC was not related to adolescents' intention to have children. At the cultural level, the VOC dimensions were only partly related to adolescents' intention to have children. The results are discussed with regard to adolescents' future family orientation and in relation to the VOC approach.
\end{abstract}

\section{Keywords}

value of children, adolescents' fertility intentions, multilevel modeling, cross-cultural study

In the present study, we explore adolescents' value of children (VOC) and their intentions to have their own children from a cross-cultural perspective. Over the past few decades, several countries have seen significant changes with regard to family size and fertility rate. Although the fertility rate has not changed significantly over the past 30 years for some countries (e.g., France, Germany, and the United States), other countries have experienced a rather dramatic decline (e.g., Indonesia, Turkey). These changes may enter into cultural models of family and thereby influence adolescents' personal future orientation (Trommsdorff \& Nauck, 2006).

Adolescents' future orientation with regard to having their own family and own children is based on personal values, perceived cultural models, and past experiences. Adolescents' future

'University of Konstanz, Konstanz, Germany

Corresponding Author:

Boris Mayer, University of Konstanz, Department of Psychology, P.O. Box 14, D-78457 Konstanz, Germany

Email:boris.mayer@uni-konstanz.de 
orientation may in turn influence a society's future. Ideas and values regarding family and having children are ideational elements that can have substantial effects in addition to and independent of structural factors, such as economic development and institutional modernization (Jayakody, Thornton, \& Axinn, 2008).

In the present study, we compare adolescents' (a) future orientation with regard to having their own children and (b) reasons for having children (VOC) across 12 cultures. Furthermore, we explore the link between the VOC and the actual intention to have children (and how many children) by separating culture-level influences from individual-level influences using random coefficient multilevel modeling. This procedure is novel and has not yet been widely used in cross-cultural psychology even though past researchers have shown that relations between constructs at the individual level often differ from relations at the cultural level of analyses (van de Vijver, van Hemert, \& Poortinga, 2008). A further contribution of this study to the VOC research is that we explore the relation between the VOC and fertility from the perspective of adolescents and their intention to have children. Adolescents' values are an important indicator of a culture's and society's future and are therefore a relevant topic of research in their own respect. In addition, adolescents usually do not yet have children. In most studies examining the relation between the VOC and fertility, researchers have measured mothers' VOC after they have given birth to some or all of their children. Using this procedure risks confounding the effects of participants' VOC on fertility with possible reciprocal effects of their fertility on VOC. In the current study, we avoid this risk by studying adolescents and their intention or plans to have children in the future.

The present study is part of the cross-cultural Value of Children and Intergenerational Relations research project, which is a replication and extension of the original cross-cultural VOC studies carried out in the 1970s at the University of Hawaii (Arnold et al., 1975). Although the focus of the original study was mainly on relations between VOC and fertility, the new VOC study also focuses on the relations between value orientations (general and family related) and parent-child relations across three generations in a cultural context (Trommsdorff, Kim, \& Nauck, 2005; Trommsdorff \& Nauck, 2005). To date, about 13,000 persons (from three connected generations: grandmothers, mothers, and adolescents) have been interviewed in 15 countries. In the current study, we use data from the samples of adolescents in 12 cultures. Data from the other three cultures were not yet available by the time of completion of the present study.

Currently, the world is divided with regard to demographic problems. The world population is on the rise and will reach 9.2 billion in 2050 (United Nations, 2007). Most of the population growth is located in cultures with a low level of economic development. In most economically developed cultures and cultures in transition, population growth has either leveled off or is decreasing. Some cultures (e.g., China, India, and Turkey) suffer from overpopulation and attempt to restrict their population growth through education and regulations. In many economically developed cultures, there is a growing public concern over the low fertility rate (e.g., Germany, Japan). This is seen as a problem with respect to several issues: the survival of the society, the relationship between older and younger generations, and the functioning of the social security systems, especially with regard to supporting the growing number of the elderly. Therefore, the question of why people want to have children is raised from concerns both about overpopulation as well as about a declining population.

Many factors influence a person's intention to have children. Having children may be viewed as a natural part of adult life. Having children involves raising and educating them, sharing one's life with them, and taking the responsibility for their well-being. Having children may also mean sharing this experience with one's spouse or partner, parents, and other family members, which fosters bonding within the family. Individual motives of having children are related to social, emotional, and familial goals. 
Sociocultural factors provide the context and opportunity structures for having (or not having) children. These factors are also related to shared values and beliefs about whether to have children and how many children one should have. Individual factors can be viewed in the context of the individual opportunity structures that vary within a given society. Relevant individual factors also concern the extent to which individuals subscribe to cultural values, norms, and beliefs.

Cross-cultural studies on adolescents' intentions to have children are important for several theoretical reasons. From a developmental psychological perspective, adolescence has been conceived of as the transition to adulthood. Recently, it has been suggested that it is rather followed by an emerging adulthood (Arnett, 2006). This kind of prolonged adolescence because of lengthy education can delay individuals from starting a career and forming a family of their own, especially in modern societies. Culture-specific developmental pathways structure adolescents' development in their value orientations, identity formation, future possible selves, and relationships with parents and peers (Gibbons \& Stiles, 2004; Ho, 1986; Rothbaum, Pott, Azuma, Miyake, \& Weisz, 2000). However, too little is known about universal aspects and cultural differences of adolescents' future orientation (Seginer, 2009; Trommsdorff, 1994), especially regarding their future offspring and family.

\section{VOC}

The VOC approach relates the nature and degree of (potential) parents' valuing of children to their motivation for having children that is evident in their fertility behavior (Arnold et al., 1975). The VOC for parents follows from the needs that children fulfill for their parents and the benefits that they provide (Hoffman \& Hoffman, 1973). A differentiation among economicutilitarian, social-normative, and emotional benefits from having children has proven empirically useful in predicting fertility within and across cultures (Arnold et al., 1975; Kagitcibasi, 1982). More recent factor analyses suggest that economic-utilitarian VOC and social-normative VOC may also combine to form a utilitarian-normative VOC (Mayer, Albert, Trommsdorff, \& Schwarz, 2005).

VOC has been conceptualized as a psychological mediator between macro-level institutional changes (industrialization, modernization) and fertility rates (e.g., Nauck, 2007). It is assumed that group-level phenomena and individual-level values and fertility decisions are linked. However, researchers dealing with the relations between the different qualities of VOC and fertility have only rarely attempted to systematically separate cultural and individual levels of analyses.

The main hypotheses of these previous studies have been that (a) the economic-utilitarian VOC is related to higher fertility because economic needs are best fulfilled by having as many children as possible (e.g., through children's help in the family and financial support in old age) and that (b) the emotional VOC (referring to affective bonds with children and the emotional gratification that the relationship with one's own children brings) is related to lower fertility because emotional needs can be fulfilled by one or two children as well as (or even better than) by many children (Caldwell, 1982).

With regard to factors influencing the different qualities of VOC, institutionalized modernization and a rising income level should be associated with a lower importance of the economicutilitarian VOC. Modernization diminishes the economic interdependencies among family members through individualized employment structures, greater outside-the-home job opportunities for women, and state-run social security systems caring for elderly people independent of their status as parents. Modernization can also lead to a higher salience of the emotional VOC. In this respect, children are expected to fulfill a need for intimacy, affiliation, and closeness. With increasing economic prosperity comes increasing attention to and efforts to fulfill emotional needs. In economically developed cultures, the economic-utilitarian VOCs presumably are minimal 
because there are few economic benefits to be expected from children, and the emotional VOC may constitute the primary reason for having children (Nauck, 2005). Nevertheless, the emotional VOC has been shown to be very important to people in many different cultures, independent of their economic development (Nauck \& Klaus, 2007).

\section{Relations Between the VOC and Fertility at the Group or Cultural Level}

At the group or cultural level, few researchers have related the VOC dimensions to fertility. Trommsdorff (2009) reported a correlation of $r=.73$ between the mean level of utilitariannormative VOC and total fertility rate across 10 cultures for mothers of adolescent children. In other studies, possible group-level relations have to be inferred from mean differences analyzed simultaneously for VOC dimensions and fertility-related variables across several groups. When comparing Turkish data from the current VOC study to the data from the original VOC studies conducted 30 years ago, Kagitcibasi and Ataca (2005) found that both the importance of the economic-utilitarian VOC and mothers' actual, desired, and ideal numbers of children have declined from 1975 to 2003, whereas the importance of the emotional VOC has increased. These results suggest a positive relation between the economic-utilitarian VOC and fertilityrelated measures and a negative relation between the emotional VOC and fertility-related measures across time.

Other studies have compared generations (within-family triads) in Germany (Mayer et al., 2005), Indonesia (Albert, Trommsdorff, Mayer, \& Schwarz, 2005), India (Mishra, Mayer, Trommsdorff, Albert, \& Schwarz, 2005), and Korea (Kim, Park, Kwon, \& Koo, 2005). These results show that grandmothers and mothers report a higher importance of the utilitariannormative VOC than do their children and grandchildren whereas the younger generation reports a higher importance of the emotional VOC. At the same time, the reported ideal number of children decreased from the older to the younger generations. Studies on urban-rural comparisons show similar results. Participants from urban samples consistently report a lower utilitariannormative VOC and lower fertility rates and, in some cases, also a higher emotional VOC than do persons from rural samples (Indonesia: Albert et al., 2005; Turkey: Kagitcibasi \& Ataca, 2005; India: Mishra et al., 2005). Though these intracultural comparisons across time, generations, and urban versus rural participants suggest that the VOC dimensions are related to fertility measures at the group level, further studies are needed to expand these analyses to include several cultures and test the relation in a correlational design.

\section{Relations Between the VOC and Fertility at the Individual Level}

Using data from the original VOC study, Kagitcibasi (1982) reported that the economic-utilitarian VOC was positively related to Turkish mothers' parity (i.e., the number of children to which a woman has given birth) whereas the emotional VOC was negatively related to parity. Nauck (2007) found an individual-level positive relation between economic-utilitarian VOC and parity and a negative relation between emotional VOC and parity in several cultures.

As outlined above, a problem with previous culture-level and individual-level studies is that the samples have mostly consisted of mothers. This approach ignores the possibility that having children may affect one's VOC rather than vice versa. A more meaningful test of whether fertility follows from VOC would be to use a longitudinal design. However, this is difficult to implement, especially for large-scale cross-cultural studies. Therefore, in the present study, we analyzed adolescents' VOC and their desire or intention to have children to avoid the problem of direction of effects (Rholes, Simpson, Blakely, Lanigan, \& Allen, 1997). 


\section{Multilevel Structure of the Relation Between the VOC and Fertility}

A problem of previous studies on the relation between the VOC and fertility-related variables is that cultural and individual levels have not been taken into account simultaneously. This is especially problematic because the relation between the VOC and fertility may be different at the individual and cultural levels. There are theoretical reasons why a negative relation between the emotional VOC and fertility behavior may be limited to the cultural level and why at the individual level a positive relationship may exist. In a study of adults from Germany, Costa Rica, and Cameroon, Chasiotis, Hofer, and Campos (2006) found that love for children positively predicted parenthood at the individual level. This should especially be the case for cultures in which the emotional values of having children are very important and the utilitarian-normative values are insignificant: When only emotional reasons for having children exist in a specific culture, people who consider those reasons important should want to have more children than should people who endorse emotional reasons to a lesser degree. This would constitute a cross-level interaction between the culture-level importance of the emotional VOC and its individual-level effect on the intended number of children in a multilevel analysis. Similarly, the utilitariannormative VOC may have a stronger effect on the desired number of children in cultures endorsing a high utilitarian-normative VOC. Furthermore, the relation between the emotional VOC and having or wanting children may be nonlinear: A positive effect may level off with rising emotional VOC because parental emotional needs may be fulfilled by one or two children just as well as by many children.

\section{Overview of Research Questions}

With respect to the number of children adolescents intend to have in the future, we expect that adolescents from cultures with a low level of economic development will intend to have relatively more children and adolescents from economically developed cultures and cultures in transition will intend to have relatively fewer children. Emotional reasons for having children should be important for adolescents in all cultures, and for economically developed cultures they may be even more important and constitute the only reasons for having children. We expect significant differences with regard to utilitarian-normative VOCs. Adolescents from cultures with a low level of economic development are expected to report higher utilitarian-normative VOC than will adolescents from transitional cultures, who in turn should report a higher importance than will adolescents from economically developed cultures. We also explore gender differences to test the hypothesis that girls will report a higher emotional VOC than will boys, whereas boys will report a higher economic-utilitarian VOC than will girls (Ruble \& Martin, 1998).

A positive relation between the utilitarian-normative VOC and the intended number of children is expected at both the individual and the cultural level. We expect no association or even a negative association between the emotional VOC and the intended number of children at the cultural level and expect a positive association at the individual level.

\section{Method}

\section{Selection of Cultures}

For cross-cultural studies, it is necessary to select cultures representing a range of diversity on theoretically relevant variables. Therefore, we included cultures from diverse geographical regions, 
Table I. Culture-Level and Individual-Level Socioeconomic Background Variables

\begin{tabular}{|c|c|c|c|c|c|c|c|c|c|c|}
\hline \multirow[b]{2}{*}{ Culture } & \multirow{2}{*}{$\begin{array}{l}\text { GDP } \\
\text { PPP }^{a} \\
U S \$\end{array}$} & \multicolumn{2}{|c|}{ Total fertility rate ${ }^{b}$} & \multicolumn{2}{|c|}{$\begin{array}{l}\text { Economic } \\
\text { status }\end{array}$} & \multicolumn{2}{|c|}{ Age } & \multicolumn{3}{|c|}{$\begin{array}{l}\text { Years of school } \\
\text { completed }\end{array}$} \\
\hline & & 1970-1975 & 2000-2005 & $M$ & $S D$ & $M$ & $S D$ & $M$ & $S D$ & $M a d j$ \\
\hline India & 2,126 & 5.3 & 3.1 & 3.16 & 1.01 & 15.94 & 1.42 & 9.18 & 4.37 & 9.04 \\
\hline Indonesia & 3,234 & 5.3 & 2.4 & 2.83 & 0.73 & 15.25 & 1.00 & 9.60 & 1.43 & 9.78 \\
\hline China & 4,091 & 4.9 & 1.7 & 2.70 & 0.75 & 13.91 & 0.93 & 8.20 & 1.17 & 9.19 \\
\hline Turkey & 7,786 & 5.3 & 2.2 & 3.13 & 0.85 & 14.80 & 1.04 & 9.20 & 1.43 & 9.67 \\
\hline $\begin{array}{l}\text { South } \\
\text { Africa }\end{array}$ & 8,477 & 5.5 & 2.8 & 2.63 & 0.87 & 14.96 & 1.21 & 9.56 & 1.39 & 9.95 \\
\hline Russia $^{\mathrm{d}}$ & ||$, 86 \mid$ & 2.0 & 1.3 & - & - & 16.09 & 1.35 & 8.92 & 1.25 & 8.53 \\
\hline Poland & 13,573 & 2.3 & 1.3 & 3.05 & 0.71 & 15.60 & 1.25 & 8.40 & 1.53 & 8.34 \\
\hline Israel & 23,845 & 3.8 & 2.9 & 3.09 & 0.72 & 15.79 & 1.35 & 9.95 & 1.53 & 9.80 \\
\hline France & 29,644 & 2.3 & 1.9 & 3.46 & 0.59 & 15.75 & 1.18 & 9.72 & 1.13 & 9.57 \\
\hline Germany & 30,496 & 1.6 & 1.3 & 3.22 & 0.59 & 15.65 & 1.04 & 9.34 & 1.13 & 9.25 \\
\hline Japan & 31,267 & 2.1 & 1.3 & 3.09 & 0.80 & 16.46 & 0.77 & 10.10 & 0.71 & 9.52 \\
\hline $\begin{array}{l}\text { United } \\
\text { States }\end{array}$ & 41,674 & 2.0 & 2.0 & 3.22 & 0.70 & 16.24 & 1.45 & 10.26 & 1.37 & 9.80 \\
\hline
\end{tabular}

a. Per capita gross domestic product purchasing power parity as of 2005 (World Bank, 2008).

b. Total fertility rate (births per woman; United Nations Development Programme, 2007).

c. $M$ adj $=$ means adjusted for adolescents' age.

d. Russia: No data available for economic status.

representing a wide range of socioeconomic development and levels of fertility (see Table 1). In the present study, we do not differentiate between cultures and countries but always use the term culture. Although we acknowledge that there are different cultural groups within countries, we believe that usage of the term culture is justified here for practical reasons and because we included typical adolescents from the respective countries.

\section{Participants}

A total of 3,348 adolescents (1,417 boys; 1,931 girls) from 12 cultures participated in the study: China ( $n=284,58 \%$ female), France $(n=199,55 \%$ female), Germany ( $n=310,56 \%$ female), India $(n=295,51 \%$ female), Indonesia $(n=300,55 \%$ female), Israel (Jews, $n=187,63 \%$ female), Japan ( $n=207,63 \%$ female), Poland ( $n=281,60 \%$ female), Russia $(n=331,55 \%$ female), South Africa ( $n=317,61 \%$ female), Turkey $(n=300,53 \%$ female), and the United States ( $n=337,64 \%$ female). In cultures where strong urban-rural differences continue to exist (i.e., China, India, Indonesia, Poland, South Africa, Turkey), samples from both rural and urban areas were included. In all other cultures, adolescents were recruited from suburban or urban regions considered typical for the cultures. Adolescents were between 13 and 19 years old, with an overall mean age of 15.52 years $(S D=1.37$ years). An ANOVA with the culture factor was significant, $F(11,3269)=96.91, p<.001, \eta^{2}=.25$. The youngest adolescents were from China $(M=13.91$ years) and the oldest were from Japan $(M=16.46$ years; see Table 1$)$.

The participants were recruited from socioeconomic backgrounds that can be considered average for the respective culture. Participants indicated their economic status relative to other people in their culture on a scale from 1 to $5(1=$ low, $2=$ lower middle, $3=$ middle, $4=$ upper middle, $5=$ upper $)$. The ANOVA with the culture factor was significant, $F(11,3280)=25.59$, $p<.001, \eta^{2}=.08$. Overall, the means ranged from about 2.5 to about 3.5 , indicating a middle economic status. The lowest economic status was reported by South African adolescents, ${ }^{1}$ the 
highest by French adolescents (see Table 1). Educational level was assessed by the completed years of schooling reported by adolescents. An ANCOVA including the age covariate showed a significant effect of the culture factor, $F(11,3191)=28.06, p<.001, \eta^{2}=.09$, and a significant effect of the age covariate, $F(1,3191)=691.88, p<.001, \eta^{2}=.18$. Because of the significant age effect, we report the corrected marginal means in addition to the original mean scores. According to these corrected scores, adolescents had completed between about 8.5 and 10 years of schooling in the respective cultures (see Table 1). Although the samples are not representative (this is impossible in countries like India where a multiplicity of ethnic groups and languages exists), they largely represent a medium socioeconomic status within the respective country.

\section{Procedure}

Adolescents completed the VOC-IR study questionnaire for adolescents (Trommsdorff, Nauck, Schwarz, Chakkarath, \& Schwenk, 2002). The data collection was carried out by research assistants from the respective cultures under the supervision of the team leaders of the collaborating research teams.

\section{Instruments}

For the present study, only the VOC scale and questions regarding intention to have children were used. All language versions were translated from the original English version into their respective target language by a bilingual native speaker of the target language. The questionnaires were then back translated, and inconsistencies were corrected in cooperation with the translators from the respective cultures.

VOC factor structure and cross-cultural equivalence. The VOC scale included economic-utilitarian VOC (e.g., "To have one more person to help your family economically"), social-normative VOC (e.g., "Because some of your older relatives feel that you should have more children"), and emotional VOC (e.g., "Because of the special feeling of love that develops between a parent and a child") from the original VOC study (Arnold et al., 1975). Additional items, including several from the Family and Fertility Survey (Pohl, 1995), were also incorporated. For 18 statements, adolescents indicated on a 5 -point scale $(1=$ not important at all, $5=$ very important $)$ how important they judged the reasons to be that people may give for wanting to have children.

The VOC instrument was tested with respect to structural equivalence across cultures (van de Vijver \& Leung, 1997). To check for cross-cultural construct equivalence, we first conducted a principal component analysis (PCA) across all participants and cultures using per culture $z$-standardized values to account for cross-cultural mean differences (Leung \& Bond, 1989), resulting in the pooled solution. The scree plot of the pooled solution suggested extracting two factors with eigenvalues of 5.93 and 2.25 and with a combined explained variance of $45.44 \%$. The first factor was made up of seven items reflecting emotional VOCs. The second factor combined eight items referring to economic-utilitarian and social-normative reasons for having children. This factor was labeled utilitarian-normative VOC. Three items showed cross-loadings (greater than .30 on the respective other factor) or no substantial loadings (see Table 2).

In a second step, a separate PCA was conducted for each culture and was target rotated to the pooled solution. We then compared the loadings of the target-rotated single solutions to the loadings of the pooled solution using the proportionality coefficient Tucker's phi. A value of .95 and higher indicates a high similarity between the culture-specific solution and the pooled solution, and a value between .90 and .95 indicates acceptable similarity (van de Vijver \& Leung, 1997). With the exception of Israel and South Africa (Tucker's phi from .59 to .83), both factors were very similar to the pooled solution in all cultures (emotional VOC: Tucker's phi from .95 to .99 ; 
Table 2. Value of Children (VOC) Factor Loadings of the Pooled Solution

\begin{tabular}{|c|c|c|}
\hline & Emotional VOC & Utilitarian-normative VOC \\
\hline $\begin{array}{l}\text { Because of the pleasure you get from watching } \\
\text { your children grow. }\end{array}$ & .79 & .10 \\
\hline Because it is a joy to have a small baby. & .77 & .10 \\
\hline $\begin{array}{l}\text { Because it is fun to have young children around } \\
\text { the house. }\end{array}$ & .76 & .11 \\
\hline $\begin{array}{l}\text { Because of the special feeling of love that } \\
\text { develops between a parent and a child. }\end{array}$ & .76 & .01 \\
\hline To have someone to love and care for. & .65 & .18 \\
\hline $\begin{array}{l}\text { Because raising children helps you to learn } \\
\text { about life and yourself. }\end{array}$ & .59 & .26 \\
\hline $\begin{array}{l}\text { Because having children increases your sense of } \\
\text { responsibility and helps you to develop. }\end{array}$ & .57 & .29 \\
\hline $\begin{array}{l}\text { Because any new family member makes your } \\
\text { family more important. }\end{array}$ & .46 & .37 \\
\hline $\begin{array}{l}\text { To have one more person to help your family } \\
\text { economically. }\end{array}$ & .06 & .72 \\
\hline To carry on the family name. & .12 & .67 \\
\hline $\begin{array}{l}\text { Because some of your older relatives feel that } \\
\text { you should have more children. }\end{array}$ & .02 & .64 \\
\hline Because a child helps around the house. & .13 & .64 \\
\hline Your children can help you when you're old. & .20 & .63 \\
\hline $\begin{array}{l}\text { Because parenthood improves your standing } \\
\text { and betters your reputation among your kin. }\end{array}$ & .24 & .62 \\
\hline $\begin{array}{l}\text { To be sure that enough children will survive to } \\
\text { adulthood. }\end{array}$ & .09 & .60 \\
\hline $\begin{array}{l}\text { When it is a duty to have children according to } \\
\text { your belief. }\end{array}$ & .17 & .56 \\
\hline $\begin{array}{l}\text { Because people with children are less likely to } \\
\text { be lonely in old age. }\end{array}$ & .31 & .54 \\
\hline $\begin{array}{l}\text { Because your life will be continued through } \\
\text { your children. }\end{array}$ & .40 & .45 \\
\hline
\end{tabular}

Principal component analysis using varimax rotation. Factor loadings in bold denote items that were included in constructing the VOC scales.

utilitarian-normative VOC: from .96 to .99 ). Thus, across the majority of cultures in the study, the two dimensions of emotional VOC and utilitarian-normative VOC proved cross-culturally equivalent. In the Israeli case, the culture-specific solution yielded three rather than two factors. This was the only culture in which the economic-utilitarian and the social-normative reasons for wanting children formed two different dimensions in addition to the emotional VOC. In South Africa, a unifactorial structure resulted with all VOC items forming a single dimension. Overall, the cross-cultural equivalence of the VOC instrument was largely confirmed.

Scale reliabilities were satisfactory to high in all cultures. For emotional VOC, Cronbach's alphas ranged from .75 to $.89(M=.83, S D=.05)$, and for utilitarian-normative VOC, reliabilities ranged from .68 to $.85(M=.80, S D=.05)$. Because reliabilities were satisfactory in Israel and South Africa, we decided to keep these cultures in the study despite their dimensional nonequivalence. Therefore, measures of emotional VOC and utilitarian-normative VOC were generated by averaging across the respective items, omitting the items that cross-loaded in the pooled factor solution. 
Intended number of children. Adolescents' intention to have children was tapped by two questions. The first asked if adolescents planned to have offspring in the future with the answer options of 1 (yes/probably), 2 (no/probably not), and 3 (I don't know). The second question assessed the number of children adolescents intended to have, in case the answer was yes in the previous question. These two questions were combined into one numerical measure of the number of children adolescents intended to have (ranging from 0 to 11 children). Adolescents who answered "I don't know" were not included in the analysis.

\section{Results}

\section{Intended Number of Children andVOC}

We used ANCOVAs to compare the intended number of children, the emotional VOC, and the utilitarian-normative VOC across cultures and genders. Adolescents' age was included as a covariate in the analyses. In addition to the original scores, analyses were also carried out using withinsubject standardized scores to account for possible culture-specific response bias in the Likert-type scales (Smith, 2004; van de Vijver \& Leung, 1997). Because the results using the ipsatized scores yielded very similar results to those with the original scores, only analyses based on the original scores are presented.

Intended number of children. The ANCOVA for intended number of children showed a significant main effect of culture, $F(11,2654)=55.38, p<.001, \eta^{2}=.19$. The gender main effect was nonsignificant, $F(1,2654)=0.01, n s$, whereas the Culture $\times$ Gender interaction effect was significant, $F(11,2654)=2.84, p<.01, \eta^{2}=.01$. The effect of the age covariate was nonsignificant, $F(1$, $2654)=0.35, n s$. Inspection of the confidence intervals of the marginal means for the culture factor indicated that Israeli adolescents wanted significantly more children (about 3.5 children) than did adolescents from all other cultures. A second group consisted of adolescents from the United States, South Africa, and France, who all wanted about 2.5 children. A third group consisted of adolescents from all the remaining cultures (who on average wanted two children) except China (who on average wanted one child). Indonesian adolescents were in between the second and the third group (see Table 3). A significant gender difference was found only in the United States, with female adolescents planning to have more children than were their male counterparts.

Figure 1 depicts the desired number of children in percentages. Israel had the highest proportion of adolescents who planned to have more than two children, followed by French, South African, and U.S. adolescents with about $50 \%$. About $30 \%$ of Japanese and about $20 \%$ of Indonesian and Polish adolescents planned to have more than two children. In India and Germany, this proportion was around $15 \%$, and in Russia and Turkey it was around $10 \%$. In China, less than $1 \%$ of adolescents wanted to have more than two children. In all cultures except China, the largest proportion of adolescents wanted to have two children.

Emotional VOC. Results for the emotional VOC showed a significant main effect of culture, $F(11,3254)=19.47, p<.001, \eta^{2}=.06$, a significant main effect of gender, $F(1,3254)=24.11$, $p<.001, \eta^{2}=.01$, and a significant Culture $\times$ Gender interaction effect, $F(11,3254)=2.24, p<.05$, $\eta^{2}=.01$. The effect of the age covariate was nonsignificant, $F(1,3254)=0.49$, ns. Inspection of the confidence intervals of the marginal means for the culture factor indicated that Indonesian adolescents reported the highest emotional VOC and that Chinese, German, Israeli, and Japanese adolescents reported the lowest emotional VOC (see Table 4). All other cultures were in between. Gender differences were significant only in the United States and in Russia, where female adolescents reported a higher emotional VOC than did their male counterparts.

Utilitarian-normativeVOC. The analysis for the utilitarian-normative VOC revealed a significant main effect of culture, $F(11,3254)=171.18, p<.001, \eta^{2}=.37$. There was also a significant 
Table 3. Culture and Gender Differences in Intended Number of Children

\begin{tabular}{|c|c|c|c|c|c|c|}
\hline \multirow[b]{2}{*}{ Culture } & \multicolumn{2}{|c|}{ Boys } & \multicolumn{2}{|c|}{ Girls } & \multicolumn{2}{|c|}{ All } \\
\hline & $M$ & $S D$ & $M$ & $S D$ & M & $S D$ \\
\hline India & 1.87 & 0.68 & 1.76 & 0.99 & $1.82_{b}$ & 0.83 \\
\hline Indonesia & 2.27 & 0.65 & 2.13 & 0.42 & $2.19_{c}^{\circ}$ & 0.54 \\
\hline China & 1.10 & 0.65 & 1.05 & 0.76 & $1.08_{a}$ & 0.71 \\
\hline Turkey & 1.90 & 1.15 & 1.75 & 0.82 & $1.82_{b}^{a}$ & 0.99 \\
\hline South Africa & 2.83 & 1.24 & 2.50 & 1.29 & $2.63_{d}^{\circ}$ & 1.28 \\
\hline Russia & 1.93 & 1.21 & 1.78 & 0.66 & $1.84_{b}$ & 0.93 \\
\hline Poland & 1.93 & 0.70 & 2.12 & 0.77 & $2.05_{b c}$ & 0.75 \\
\hline Israel & 3.53 & 2.12 & 3.34 & 1.69 & $3.4 \mathrm{I}_{\mathrm{e}}^{0 c}$ & 1.85 \\
\hline France & 2.49 & 1.08 & 2.67 & 0.85 & $2.59_{d}^{e}$ & 0.95 \\
\hline Germany & 1.61 & 0.80 & 1.86 & 0.95 & $1.76_{b}$ & 0.90 \\
\hline Japan & 1.83 & 0.85 & 1.96 & 1.21 & $1.92_{\mathrm{b}}^{\circ}$ & 1.10 \\
\hline United States & 2.45 & 1.29 & 2.89 & 1.36 & $2.74_{d}$ & 1.35 \\
\hline
\end{tabular}

$N=2,679$; boys $n=1,109$; girls $n=1,570$. Means in the "all" column that share a common subscript do not differ significantly in comparison of marginal means of the culture main effect. Cultures are listed according to their GDP in ascending order.

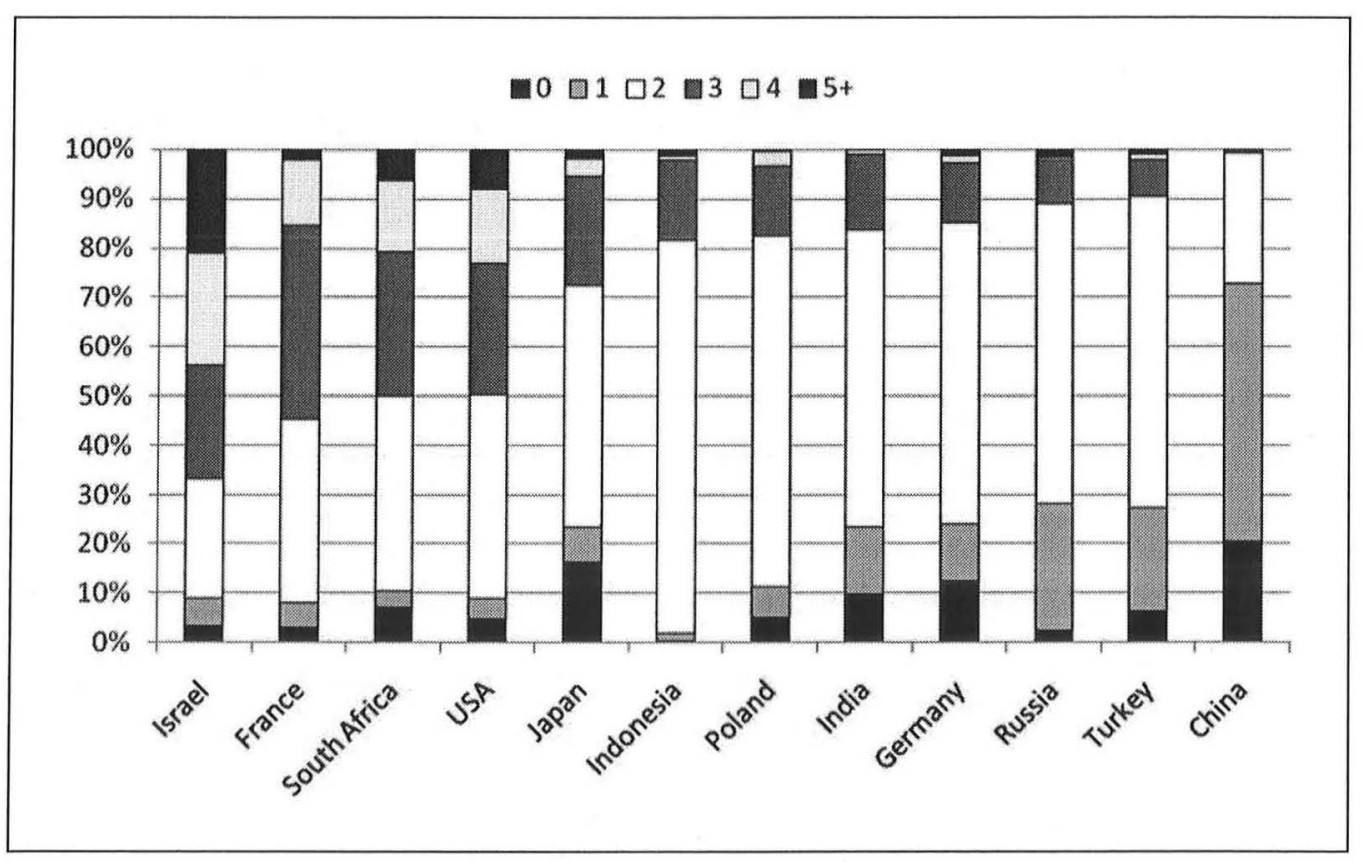

Figure I. Cultural differences in adolescents' intended number of children (percentages)

Adolescents who reported wanting to have more than 5 children are included in the $5+$ category in this illustration.

gender main effect, $F(1,3254)=26.05, p<.001, \eta^{2}=.01$, as well as a significant Culture $\times$ Gender interaction effect, $F(11,3254)=2.33, p<.01, \eta^{2}=.01$. For the age covariate, a significant negative effect resulted $(B=-.05, S E=.01), F(1,3254)=19.55, p<.001, \eta^{2}=.01$. The age-adjusted means differed only slightly from the original scores. Inspection of the confidence intervals of the marginal means for the culture factor indicated that South African, Indonesian, and Indian adolescents showed the highest utilitarian-normative VOC, followed by Russian 
Table 4. Culture and Gender Differences in Emotional Value of Children

\begin{tabular}{|c|c|c|c|c|c|c|}
\hline \multirow[b]{2}{*}{ Culture } & \multicolumn{2}{|c|}{ Boys } & \multicolumn{2}{|c|}{ Girls } & \multicolumn{2}{|c|}{ All } \\
\hline & $M$ & $S D$ & $M$ & $S D$ & M & $S D$ \\
\hline India & 4.06 & 0.76 & 4.15 & 0.78 & $4.1 I_{b c}$ & 0.77 \\
\hline Indonesia & 4.09 & 0.48 & 4.24 & 0.44 & $4.17_{c}^{\circ}$ & 0.47 \\
\hline China & 3.70 & 0.85 & 3.76 & 0.90 & $3.73_{\mathrm{a}}$ & 0.88 \\
\hline Turkey & 4.13 & 0.57 & 4.08 & 0.76 & 4. $10_{\mathrm{bc}}^{\mathrm{d}}$ & 0.68 \\
\hline South Africa & 3.98 & 1.07 & 4.04 & 0.91 & $4.0 \mathrm{I}_{\mathrm{bc}}^{\mathrm{dc}}$ & 0.98 \\
\hline Russia & 3.81 & 0.73 & 4.09 & 0.55 & $3.96_{b}$ & 0.65 \\
\hline Poland & 3.97 & 0.60 & 4.06 & 0.63 & $4.02_{b c}$ & 0.62 \\
\hline Israel & 3.42 & 0.85 & 3.65 & 0.72 & $3.56_{a}$ & 0.78 \\
\hline France & 3.91 & 0.63 & 4.13 & 0.52 & $4.03_{\mathrm{bc}}$ & 0.58 \\
\hline Germany & 3.56 & 0.70 & 3.78 & 0.65 & $3.68_{a}$ & 0.68 \\
\hline Japan & 3.74 & 0.92 & 3.60 & 0.93 & $3.65_{\mathrm{a}}^{\mathrm{a}}$ & 0.92 \\
\hline United States & 3.88 & 0.86 & 4.23 & 0.63 & $4.10_{\mathrm{bc}}$ & 0.74 \\
\hline
\end{tabular}

$N=3,279$; boys $n=1,387$; girls $n=1,892$. Means in the "all" column that share a common subscript do not differ significantly in comparison of marginal means of the culture main effect. Cultures are listed according to their GDP in ascending order.

Table 5. Culture and Gender Differences in Utilitarian-Normative Value of Children

\begin{tabular}{|c|c|c|c|c|c|c|}
\hline \multirow[b]{2}{*}{ Culture } & \multicolumn{2}{|c|}{ Boys } & \multicolumn{2}{|c|}{ Girls } & \multicolumn{2}{|c|}{ All } \\
\hline & $M$ & $S D$ & M & $S D$ & M & $S D$ \\
\hline India & 3.54 & 0.88 & 3.49 & 0.95 & $3.5 \mathrm{I}_{\mathrm{d}}$ & 0.92 \\
\hline Indonesia & 3.43 & 0.56 & 3.50 & 0.60 & $3.47_{d}$ & 0.58 \\
\hline China & 2.49 & 0.81 & 2.32 & 0.72 & $2.39_{b}$ & 0.76 \\
\hline Turkey & 2.69 & 0.87 & 2.32 & 0.88 & $2.49_{b}$ & 0.89 \\
\hline South Africa & 3.60 & 0.88 & 3.55 & 0.88 & $3.57_{d}$ & 0.88 \\
\hline Russia & 3.01 & 0.75 & 2.71 & 0.74 & $2.85_{c}$ & 0.76 \\
\hline Poland & 2.50 & 0.73 & 2.45 & 0.80 & $2.47_{b}$ & 0.77 \\
\hline Israel & 2.52 & 0.63 & 2.50 & 0.72 & $2.5 \mathrm{I}_{\mathrm{b}}$ & 0.69 \\
\hline France & 2.08 & 0.76 & 1.88 & 0.55 & $1.97 \mathrm{a}$ & 0.66 \\
\hline Germany & 1.93 & 0.57 & 1.80 & 0.57 & $1.86 \mathrm{a}$ & 0.58 \\
\hline Japan & 2.05 & 0.62 & 1.96 & 0.65 & $1.99 \mathrm{a}$ & 0.64 \\
\hline United States & 2.50 & 0.83 & 2.18 & 0.82 & $2.30_{b}$ & 0.84 \\
\hline
\end{tabular}

$N=3,279$; boys $n=1,387$; girls $n=1,892$. Means in the "all" column that share a common subscript do not differ significantly in comparison of marginal means of the culture main effect. Cultures are listed according to their GDP in ascending order.

adolescents and then by Israeli, Turkish, Polish, Chinese, and U.S. adolescents. French, German, and Japanese adolescents reported the lowest scores with regard to utilitarian-normative VOC (see Table 5). Only in Turkey, the United States, and Russia did male adolescents report a significantly higher utilitarian-normative VOC than did their female counterparts.

\section{Multilevel Modeling of the VOC and Intended Number of Children}

To take into account culture-level and individual-level relations between the different VOC dimensions and the desired number of children simultaneously, we applied multilevel random coefficient modeling (Kreft \& de Leeuw, 1998; Luke, 2004). Because the age covariate was not 
significant in predicting the intended number of children (see above), it was not included in the multilevel analysis. In addition, because there were very few gender differences with respect to the intended number of children and the VOC dimensions, gender was also not included in the analysis. Additional separate multilevel analyses for boys and girls showed similar results to the model including the overall sample.

In a multilevel model with two predictors at the individual as well as at the cultural level, two different kinds of regression equations are estimated: an individual-level (Level 1) equation, $Y_{i j}=\beta_{0 j}+\beta_{1 j} X_{j}+\beta_{2 j} Y_{j}+r_{i j}$, and culture-level (Level 2) equations to predict the $\beta$ coefficients (intercept and slopes) of the Level 1 equation, $\beta_{0 j}=\gamma_{00}+\gamma_{01} V_{j}+\gamma_{02} W_{j}+u_{0 j} ; \beta_{1 j}=\gamma_{10}+\gamma_{11} V_{j}+$ $\gamma_{12} W_{j}+u_{1 j}$; and $\beta_{2 j}=\gamma_{20}+\gamma_{21} V_{j}+\gamma_{22} W_{j}+u_{2 j}$. Following the suggestions of Luke (2004), we proceeded in a stepwise fashion starting with the variance component model or null model (only intercepts and error terms at both levels). Next, a model with only individual-level predictors was estimated, followed by adding the culture-level predictors in the final model.

In the present study, we assume measurement isomorphism of the VOC construct at the individual and cultural levels (Fontaine, 2008; van de Vijver et al., 2008) on the basis of previous studies that have employed the construct at both levels of analysis. The predictors at the individual level are the same as those at the cultural level. Thus, culture-level predictors are derived from aggregated individual scores (van de Vijver et al., 2008). This approach allows us to test whether the relation between two (or more) variables may differ between individual and cultural levels (Fontaine, 2008). We entered individual-level predictors group centered to remove all culture-level variance from the individual-level predictors (Kreft, de Leeuw, \& Aiken, 1995). Thus, the regression coefficient of the individual-level predictors represented the within-culture average effect across all cultures.

The model presented above is the generic multilevel model with random errors at the cultural level (Luke, 2004). This allows us to test (a) whether there is a significant variation of the individual-level coefficients across cultures and (b) whether the variation remains significant even after including predictors at the cultural level that we hypothesize should explain this variation. Random coefficient multilevel modeling requires a substantial number of cultures to obtain reliable estimates and to have enough statistical power to detect significant relations. The 12 cultures included in the current study are adequate to apply multilevel modeling (Nezlek, 2006). The relatively large sample sizes within cultural groups may help to obtain more statistical power according to simulation studies (Kreft \& de Leeuw, 1998).

For the multilevel analysis, the program HLM 6 was used (Raudenbush, Bryk, Cheong, Congdon, \& du Toit, 2004) and full maximum likelihood estimation was applied. The results of the null model showed a significant between-variance component of $u_{0 j}=.33, \chi^{2}(11)=660.70$, $p<.001$, and a residual within-variance component of $r_{i j}=1.11$. Thus, the proportion of the between-variance component to the overall variance in the model was $22.9 \%$. Therefore, about one fourth of the variation in the intended number of children reflected cross-cultural differences.

In the next step, we used the emotional VOC and utilitarian-normative VOC variables as predictors at the individual level to assess whether the variance components of their respective slopes were significant. Only if there is significant between-culture variation with respect to a Level 1 coefficient are the culture-level predictions meaningful. The results of this individuallevel model showed significant variance components for the slope of the emotional VOC $\left(u_{l j}\right)$, $\chi^{2}(11)=58.43, p<.001$, but not for the slope of the utilitarian-normative $\operatorname{VOC}\left(u_{2 j}\right), \chi^{2}(11)=$ $15.83, n s$. In the final model, only culture-level predictors for the intercept and for the slope of the emotional VOC were introduced and the slope for utilitarian-normative VOC was fixed.

The results of the final model showed that at the individual level there was a significant positive effect of the emotional VOC $\left(\gamma_{10}=.31\right)$ on the intended number of children, whereas there 
Table 6. Parameter Estimates of Random Coefficient Multilevel Models: Value of Children (VOC) Variables Predicting Intended Number of Children at Individual and Cultural Levels

\begin{tabular}{|c|c|c|c|c|c|}
\hline & Coeff. & SE & $T$ & $d f$ & $p$ \\
\hline \multicolumn{6}{|l|}{ For intercept $\left(\beta_{0 ;}\right)$} \\
\hline Intercept $\left(\gamma_{00}\right)$ & 2.16 & 0.17 & 12.99 & 9 & $<.001$ \\
\hline CM emotional VOC $\left(\gamma_{01}\right)$ & -0.05 & 1.01 & -0.05 & 9 & .96 \\
\hline CM utilitarian-normative VOC $\left(\gamma_{02}\right)$ & 0.08 & 0.33 & 0.26 & 9 & .80 \\
\hline \multicolumn{6}{|l|}{ For emotional VOC slope $\left(\beta_{1 \mathrm{l}}\right)$} \\
\hline Intercept $\left(\gamma_{10}\right)$ & 0.31 & 0.04 & 8.53 & 9 & $<.001$ \\
\hline CM emotional VOC $\left(\gamma_{11}\right)$ & 0.06 & 0.22 & 0.28 & 9 & .78 \\
\hline $\begin{array}{l}\text { CM utilitarian-normative VOC }\left(\gamma_{12}\right) \\
\text { For utilitarian-normative VOC slope }\left(\beta_{2 j}\right)\end{array}$ & -0.28 & 0.07 & -4.22 & 9 & $<.01$ \\
\hline Intercept $\left(\gamma_{20}\right)$ & 0.01 & 0.03 & 0.37 & 2720 & .71 \\
\hline CM emotional VOC $\left(\gamma_{21}\right)$ & - & - & - & - & \\
\hline CM utilitarian-normative VOC $\left(\gamma_{22}\right)$ & - & - & - & - & \\
\hline
\end{tabular}

$C M=$ culture mean. Level I coefficients are not estimated directly but through their Level 2 components (i.e., $\beta_{0 j}$, $\beta_{1 j}$, and $\beta_{2 j}$ are estimated via their intercepts $\gamma_{00}, \gamma_{10}, \gamma_{20}$, respectively).

was no significant effect of the utilitarian-normative VOC $\left(\gamma_{20}=.01\right.$, see Table 6$)$. The individuallevel predictors explained $5.7 \%$ of the Level 1 residual variance $\left(r_{i j}\right)$.

The culture-level effects of the emotional VOC and the traditional VOC on the intercept (i.e., on the intended number of children outcome variable) were both nonsignificant (see Table 6). Furthermore, we found a significant negative cross-level interaction effect of culture-level utilitariannormative VOC on the individual-level slope of emotional VOC $\left(\gamma_{12}=-.28\right)$. The higher a culture was on the utilitarian-normative VOC, the lower was the individual-level positive effect of the emotional VOC on the intended number of children. This cross-level interaction explained a large part of the variation in the individual-level slope of the emotional VOC as reflected in the much lower (but still significant) variance component in the final model $\left(u_{l j}\right), \chi^{2}(9)=17.67, p<.05$.

Finally, to test for nonlinear effects of the VOC at the individual level, we included a quadratic trend in the individual-level HLM model. This was done for emotional VOC and utilitariannormative VOC separately to avoid interaction effects (Hair, Black, Babin, Anderson, \& Tatham, 2006). A significant negative quadratic trend resulted for emotional VOC $(B=-.16, S E=.04, T=$ $-3.97, d f=11, p<.01)$. Thus, the positive linear effect of the emotional VOC on the intended number of children was attenuated by higher values of emotional VOC. For the utilitarian-normative VOC, a nonsignificant quadratic effect resulted $(B=-.03, S E=.02, T=-1.08, d f=11, n s)$.

\section{Discussion}

In this study, we explored cross-cultural differences and multilevel relations of adolescents' VOC and their intention to have children across 12 cultures. The results show that similarities prevail with respect to the intended number of children and the importance of the emotional VOC. However, we found substantial differences in the importance of the utilitarian-normative VOC. The results of the multilevel analyses show that only the combination of data from the individual and cultural levels allows for a clear picture of the relation between the VOC and fertility-related measures.

Few cross-cultural differences were found with regard to the number of children adolescents would like to have in the future. With the exception of Israel and China, adolescents from all cultures preferred to have between two and three children. The high number in Israel and the low 
number in China may be due to their respective political situations. In both cases, larger societal forces involving group safety and survival may be at work. In China, safety concerns stem from scarce resources and the inability to support a growing population as well as from punishments for violating the one-child policy. In Israel, safety concerns result from being surrounded by much more populated and antagonistic countries. U.S. and French adolescents reported a higher number of desired children than did adolescents from the other European cultures. This result is in line with the fact that the national fertility rates of these two countries are higher (around 2.0) than those in the rest of Europe (around 1.3). It is interesting, however, that French and American adolescents want to have more children than even Indian, Indonesian, and Turkish adolescents; the latter live in countries with rapidly declining but nevertheless still relatively high fertility rates (Trommsdorff \& Nauck, 2006). This shows that the expected number of children corresponds more to societal trends than to current fertility rates, reflecting ideational aspects of changing family models (Jayakody et al., 2008).

The results show few cross-cultural differences with regard to adolescents' emotional VOCs. Adolescents from all 12 cultures held emotional VOCs in high regard. The rather uniform high endorsement of the emotional VOC is in line with the notion that the emotional VOC is relatively independent of the cultural background of adolescents. Similar results have been reported in previous studies (Nauck \& Klaus, 2007).

Large differences were found with respect to the utilitarian-normative VOC. Adolescents from India, Indonesia, and South Africa regard utilitarian-normative VOC as being much more important than do adolescents from the other cultures. Adolescents from Russia, Israel, Turkey, Poland, China, and the United States take a medium position on this measure, and the Western European and Japanese adolescents report the lowest values. Utilitarian-normative VOCs are important in cultures with a low level of economic development (South African adolescents are of low economic status despite the culture's overall medium level of economic development) and are less important in transitional cultures. Utilitarian-normative VOCs are least important in economically developed cultures, although the relatively high importance of utilitarian-normative values reported by U.S. adolescents is an exception here. Because all cultures with a high endorsement of utilitarian-normative VOC included rural participants, the question arises of whether the negative relation between GDP and culture-level utilitarian-normative VOC may be a result of the high proportion of rural participants in those cultures. However, additional analyses showed that this negative relation was also found when including only urban participants. ${ }^{2}$ The obtained cross-cultural differences are in accordance with our hypotheses and with previous findings. Overall, few gender differences in the desired number of children and the VOC dimensions appeared.

\section{Multilevel Relations Between the VOC and the Intended Number of Children}

With regard to the influence of adolescents' VOC on their intention to have children, results show that there is an individual-level positive effect of the emotional VOC. On average across all cultures, adolescents reporting a higher emotional VOC want to have more children than do those for whom the emotional VOC is less important. However, this positive relation was attenuated by higher values of emotional VOC. This result is in line with Caldwell's (1982) notion that emotional needs may be satisfied by having one or two children, which thus results in a nonlinear relation between the emotional VOC and the desired number of children. Furthermore, the positive effect of the emotional VOC is lower in cultures with a high importance of the utilitariannormative VOC. This is in accordance with our argument that a positive relation between 
emotional VOC and the number of children is especially likely in cultures for which the importance of the utilitarian-normative VOC is negligible.

Contrary to our hypotheses, there were no individual-level or culture-level effects of the utilitarian-normative VOC on adolescents' desire to have children. One reason for this may be that most of the participants in this study lived in urban settings. Utilitarian-normative values may have a different meaning in rural as contrasted to urban settings. However, an additional multilevel analysis (not reported here in detail) indicated that there are also no significant effects of the utilitarian-normative VOC at the individual or cultural levels when including only rural participants (from the six cultures including rural participants). We speculate that perhaps adolescents do not focus on utilitarian-normative VOCs when they consider having their own children because these reasons also include costs arising from not having children (e.g., less old-age security, less social status). It is possible that these costs are too far away from adolescents' current life situation to be pertinent whereas the emotional benefits of having children are more salient. Nevertheless, in cultures with a low level of economic development, utilitarian-normative reasons are important even though they are not related to the intended number of children. Thus, cultural norms may remain strong while losing their relevance for (intended) fertility behavior.

Why were there no significant culture-level effects on the intended number of children in this study? An inspection of the culture means of the VOC and the intended number of children revealed that of all the cultural groups, Israeli adolescents reported the lowest emotional VOC and the highest intended number of children, thereby possibly counteracting a positive culturelevel relation between these two variables in the remaining cultures. An additional random coefficients model with the remaining 11 cultures showed that a marginally significant positive culture-level effect of the emotional VOC on the intended number of children resulted when Israel was not included. ${ }^{3}$ Thus, there may actually be a positive culture-level relation between emotional VOC and the intended number of children. In cultures favoring emotional interdependence, the motive for bonding with one's own children (through having them in the first place) may be higher than in cultures favoring emotional independence. Further analyses testing this hypothesis are beyond the scope of this study.

Overall, the positive individual-level and maybe even culture-level relations between emotional VOC and the intended number of children suggest that individuals who love children more and cultures with an overall high importance of the emotional VOC also want to have more children (at the cultural level this includes shared meanings and shared intentions). These results are only partly in accordance with theorizing in the VOC model (Kagitcibasi, 1982; Nauck, 2007) in which a negative association between the emotional VOC and fertility is assumed and has been found in several studies. However, these positive relations may be especially relevant for adolescents and their plans for having children and cannot be generalized to adult parents who already have children (Rholes et al., 1997). Furthermore, the positive relation may be especially valid for the first two children as the negative quadratic effect of emotional VOC on fertility intentions at the individual level suggests.

Limitations of this study center on the adolescents' self-reports regarding their VOCs and intentions to have their own children in the future. The best validation of these verbal reports would be their actual behavior. The actual decision to give birth to a child depends on many factors beside intentions and plans. We did not take into account other individual-level factors that may be related to the intention to have children (e.g., personality, number of siblings) as well as other culture-level factors (e.g., Hofstede's dimensions). The strength of this study is that it provides cross-cultural insight into adolescents' future orientation regarding parenthood and the relation between values and future intentions. This insight is based on the usually neglected simultaneous analyses of data from the individual and cultural levels. 
To conclude, the current study shows that in most cultures adolescents appear to be strongly oriented toward having a future family. The vast majority not only want to have children in the future but also want to have two or more children. There seems to be a general agreement that two children represents an ideal number. About three decades ago, Darroch, Meyer, and Singarimbun (1981) claimed that "two [children] are not enough" for Indonesians, as the title of their report on the (original) Indonesian VOC study nicely illustrates. Nowadays, Indonesian adolescents seem to consider two children to be "enough." In contrast, adolescents from cultures with very low fertility levels (e.g., Western Europe and Japan) may wish to have two children (instead of one), presumably to ensure that the child has a sibling and to be able to have children of both genders. Whether they will really have more children than the current belowreplacement fertility rates in these countries suggest is a question for future research. The current study also showed that the traditional conceptualization of VOC effects on fertility has to be reconsidered: The emotional VOC seems to be more important for fertility (intentions) than previous studies have suggested, especially-but not restricted to-cultures in which the utilitarian-normative VOC is not (any more) important. The utilitarian-normative reasons for having children did not have any effects on adolescents' fertility intentions at either the cultural level or the individual level.

\section{Outlook and Future Studies}

Adolescents' goals with regard to having their own family are an important factor for a society's future with respect to the dominating family model. In many collectivistic cultures, to have a family of one's own is a normative developmental task. In individualistic cultures, this question is dealt with by searching for an option that promises to satisfy one's individual needs of independence and family life in an optimal way. When children are primarily desired for emotional reasons, this may affect child-rearing goals and the parent-child relationship. One question to be explored in further studies is whether in those cultures emphasizing "a lens of individuation" (Rothbaum et al., 2000, p. 1123), adolescents' motivation to have children is related to the goal not only to satisfy individual emotional needs but also to satisfy the emotional needs of the child. Future research within the VOC study will attempt to clarify the assumed associations among general cultural values (e.g., individualism, collectivism, family values), the quality of VOC, and parent-child relationships.

\section{Acknowledgments}

We would like to thank the collaborators who carried out the study in the respective countries: Gang Zheng, Shaohua Shi, and Hong Tang (People's Republic of China); Colette Sabatier and Lyda Lannegrand-Willems (France); Ramesh Mishra (India); Lieke Wisnubrata, Samsunuwijati Marat, Kusdwiratri Setiono, and Peter R. Nelwan (Indonesia); Asher Ben-Arieh and Muhammad M. Haj-Yahia (Israel and the Palestinian Authority); Katarzyna Lubiewska, Ludmila Zajac-Lamparska, and Anna Rokowska (Poland); Zaretkhan Kh.-M. Saralieva, Vladimir A. Blonin, and Alexandre A. Iudin (Russia); Karl Peltzer (South Africa); Cigdem Kagitcibasi and Bilge Ataca (Turkey); and Wolfgang Friedlmeier and Mihaela Friedlmeier (United States). Data from Japan were collected by Chiaki Yamada as part of her master's thesis supervised by Collette Sabatier, University Victor Segalen, France. The authors thank two anonymous reviewers as well as Uichol Kim, Wolfgang Friedlmeier, and Karl Peltzer for their valuable comments on an earlier version of the article and Holly Bunje for assistance in editing the manuscript.

\section{Declaration of Conflicting Interests}

The author(s) declared no potential conflicts of interest with respect to the authorship and/or publication of this article. 


\section{Funding}

This study is part of the of the cross-cultural and interdisciplinary research project "Value of Children and Intergenerational Relations" (principal investigators Gisela Trommsdorff, University of Konstanz, and Bernhard Nauck, Chemnitz University of Technology). For seven countries (People's Republic of China, Germany, Indonesia, Israel and the Palestinian Authority, Poland, Turkey, the United States), the study was funded by the German Research Foundation (TR 169/9-1, -2, -3 and NA 164/9-1, -3, -4). In India, the study was cofunded by the University of Konstanz and the German Research Foundation. In France, the study was funded by the University Victor Segalen, Bordeaux; in Russia by the Lobatchevskij State University, Nizhnij Novgorod; and in South Africa by the University of Limpopo.

\section{Notes}

1. Participants in South Africa were recruited from the Northern Sotho cultural group (Limpopo Province), whose standard of living is considerably below the South African average (Sam, Peltzer, \& Mayer, 2005).

2. The correlation between culture-level utilitarian-normative value of children (VOC) and per capita GDP was $r=-.73, p<.01$ (all participants) and $r=-.63, p<.05$ (urban participants only).

3. Culture-level effect of emotional VOC on the intended number of children in a multilevel model without Israel was $\gamma_{01}=1.76, S E=0.79, T=2.21, d f=8, p=.06$.

\section{References}

Albert, I., Trommsdorff, G., Mayer, B., \& Schwarz, B. (2005). Value of children in urban and rural Indonesia: Socio-demographic indicators, cultural aspects and empirical findings. In G. Trommsdorff \& B. Nauck (Eds.), The value of children in cross-cultural perspective: Case studies from eight societies (pp. 171-207). Lengerich, Germany: Pabst Science.

Arnett, J. J. (2006). Emerging adulthood: The winding road from the late teens through the twenties. Oxford, UK: Oxford University Press.

Arnold, F., Bulatao, R. A., Buripakdi, C., Chung, B. J., Fawcett, J. T., Iritani, T., Lee, S. J., \& Wu, T.-S. (1975). The value of children. A cross-national study (Vol. 1). Honolulu, HI: East-West Population Institute.

Caldwell, J. C. (1982). The theory of fertility decline. London, UK: Academic Press.

Chasiotis, A., Hofer, J., \& Campos, D. (2006). When does liking children lead to parenthood? Younger siblings, implicit prosocial power motivation, and explicit love for children predict parenthood across cultures. Journal of Cultural and Evolutionary Psychology, 4, 95-123.

Darroch, R. K., Meyer, P. A., \& Singarimbun, M. (1981). Two are not enough: The value of children to Javanese and Sundanese parents. Honolulu, HI: East-West Population Institute.

Fontaine, J. R. J. (2008). Traditional and multilevel approaches in cross-cultural research: An integration of methodological frameworks. In F. J. R. van de Vijver, D. A. van Hemert, \& Y. H. Poortinga (Eds.), Multilevel analysis of individuals and cultures (pp. 65-92). Mahwah, NJ: Lawrence Erlbaum.

Gibbons, J. L., \& Stiles, D. A. (2004). The thoughts of youth: An international perspective on adolescents' ideal persons. Greenwich, CT: Information Age.

Hair, J. F., Black, W. C., Babin, B. J., Anderson, R. E., \& Tatham, R. L. (2006). Multivariate data analysis (6th ed.). Upper Saddle River, NJ: Pearson/Prentice Hall.

Ho, D. Y. F. (1986). Chinese patterns of socialization: A critical review. In M. H. Bond (Ed.), The psychology of the Chinese people (pp. 1-37). Oxford, UK: Oxford University Press.

Hoffman, L. W., \& Hoffman, M. L. (1973). The value of children to parents. In J. T. Fawcett (Ed.), Psychological perspectives on population (pp. 19-77). New York, NY: Basic Books.

Jayakody, R., Thornton, A., \& Axinn, W. G. (Eds.). (2008). International family change. Ideational perspectives. Mahwah, NJ: Lawrence Erlbaum.

Kagitcibasi, C. (1982). The changing value of children in Turkey. Honolulu, HI: East-West Population Institute. 
Kagitcibasi, C., \& Ataca, B. (2005). Value of children and family change: A three-decade portrait from Turkey. Applied Psychology: An International Review, 54, 317-337.

Kim, U., Park, Y. S., Kwon, Y. E., \& Koo, J. S. (2005). Values of children, parent-child relationship, and social change in Korea: Indigenous, psychological, and cultural analysis. Applied Psychology: An International Review, 54, 313-316.

Kreft, I., \& de Leeuw, J. (1998). Introducing multilevel modeling. London, UK: Sage.

Kreft, I., de Leeuw, J., \& Aiken, L. S. (1995). The effect of different forms of centering in hierarchical linear models. Multivariate Behavioral Research, 30, 1-22.

Leung, K., \& Bond, M. H. (1989). On the empirical identification of dimensions for cross-cultural comparisons. Journal of Cross-Cultural Psychology, 20, 133-152.

Luke, D. A. (2004). Multilevel modeling. Thousand Oaks, CA: Sage.

Mayer, B., Albert, I., Trommsdorff, G., \& Schwarz, B. (2005). Value of children in Germany: Dimensions, comparison of generations, and relevance for parenting. In G. Trommsdorff \& B. Nauck (Eds.), The value of children in cross-cultural perspective: Case studies from eight societies (pp. 43-65). Lengerich, Germany: Pabst Science.

Mishra, R., Mayer, B., Trommsdorff, G., Albert, I., \& Schwarz, B. (2005). The value of children in urban and rural India: Cultural background and empirical results. In G. Trommsdorff \& B. Nauck (Eds.), The value of children in cross-cultural perspective: Case studies from eight societies (pp. 143-170). Lengerich, Germany: Pabst Science.

Nauck, B. (2005). Changing value of children: An action theory of fertility behavior and intergenerational relationships in cross-cultural comparison. In W. Friedlmeier, P. Chakkarath, \& B. Schwarz (Eds.), Culture and human development. The importance of cross-cultural research to the social sciences (pp. 183-202). New York, NY: Hove.

Nauck, B. (2007). Value of children and the framing of fertility: Results from a cross-cultural comparative survey in 10 societies. European Sociological Review, 23, 615-629.

Nauck, B., \& Klaus, D. (2007). The varying value of children. Empirical results from eleven societies in Asia, Africa, and Europe. Current Sociology, 55, 487-503.

Nezlek, J. B. (2006, July). Principles of multilevel modeling for cross-cultural research. Paper presented at the 18th International Congress of the International Association for Cross-Cultural Psychology, Isle of Spetses, Greece.

Pohl, K. (1995). Design und Struktur des deutschen FFS. Materialien zur Bevölkerungswissenschaft: Familienbildung und Kinderwunsch in Deutschland, Heft $82 a$ [Design and structure of the German FFS. Materials for the demographic sciences: Family formation and desire to have children in Germany, Issue 82a]. Wiesbaden, Germany: Bundesinstitut für Bevölkerungsforschung.

Raudenbush, S. W., Bryk, A. S., Cheong, Y. F., Congdon, R., \& du Toit, M. (2004). HLM 6: Hierarchical linear and nonlinear modeling. Lincolnwood, IL: Scientific Software International.

Rholes, W. S., Simpson, J. A., Blakely, B. S., Lanigan, L., \& Allen, E. A. (1997). Adult attachment styles, the desire to have children, and working models of parenthood. Journal of Personality, 65, 357-385.

Rothbaum, F., Pott, M., Azuma, H., Miyake, K., \& Weisz, J. (2000). The development of close relationships in Japan and the United States: Paths of symbiotic harmony and generative tension. Child Development, $71,1121-1142$.

Ruble, D. D., \& Martin, C. L. (1998). Gender development. In W. Damon \& N. Eisenberg (Eds.), Handbook of child psychology (Vol. 3, 5th ed., pp. 933-1016). New York, NY: John Wiley.

Sam, D. L., Peltzer, K., \& Mayer, B. (2005). The changing values of children and preferences regarding family size in South Africa. Applied Psychology: An International Review, 54, 355-377.

Seginer, R. (2009). Future orientation: Developmental and ecological perspectives. New York, NY: Springer.

Smith, P. B. (2004). Acquiescent response bias as an aspect of cultural communication style. Journal of Cross-Cultural Psychology, 35, 29-49. 
Trommsdorff, G. (1994). Future time perspective and control orientation: Social conditions and consequences. In Z. Zaleski (Ed.), Psychology of future orientation (pp. 39-62). Lublin, Poland: Towarzystwo Naukowe KUL.

Trommsdorff, G. (2009). A social change and a human development perspective on the value of children. In S. Bekman \& A. Aksu-Koc (Eds.), Perspectives on human development, family and culture (pp. 86-107). Cambridge, UK: Cambridge University Press.

Trommsdorff, G., Kim, U., \& Nauck, B. (Eds.). (2005). Factors influencing value of children and intergenerational relations in times of social change: Analyses from psychological and socio-cultural perspectives [Special issue]. Applied Psychology: An International Review, 54(3).

Trommsdorff, G., \& Nauck, B. (Eds.). (2005). The value of children in cross-cultural perspective: Case studies from eight societies. Lengerich, Germany: Pabst Science.

Trommsdorff, G., \& Nauck, B. (2006). Demographic changes and parent-child relationships. Parenting: Science and Practice, 6, 343-360.

Trommsdorff, G., Nauck, B., Schwarz, B., Chakkarath, P., \& Schwenk, O. (2002). VOC-IR Questionnaire for Adolescents. Unpublished questionnaire, University of Konstanz and University of Chemnitz, Germany.

United Nations. (2007). World population prospects. The 2006 revision. New York, NY: Author.

United Nations Development Programme. (2007). Human development report 2007/2008-Fighting climate change: Human solidarity in a divided world. New York, NY: Palgrave Macmillan.

van de Vijver, F. J. R., \& Leung, K. (1997). Methods and data analysis for cross-cultural research. Thousand Oaks, CA: Sage.

van de Vijver, F. J. R., van Hemert, D. A., \& Poortinga, Y. H. (2008). Conceptual issues in multilevel models. In F. J. R. van de Vijver, D. A. van Hemert, \& Y. H. Poortinga (Eds.), Multilevel analysis of individuals and cultures (pp. 3-26). Mahwah, NJ: Lawrence Erlbaum.

World Bank. (2008). Global purchasing power parities and real expenditures. Washington, DC: Author.

\section{Bios}

Boris Mayer received his doctorate in psychology at the University of Konstanz, where he is currently a lecturer of psychological research methods. His research interests include the development of adolescents and families in cultural context, effects of globalization and social change, autonomy and relatedness in adolescent development, and cross-cultural research methods.

Gisela Trommsdorff is professor in the Department of Psychology, University of Konstanz; research professor, DIW Berlin (GSOEP); and president, German-Japanese Society for Social Sciences. Her research interests include cross-cultural studies on values, intergenerational relations, development of self-regulation, prosocial motivation, and emotions. 